\title{
Pharmacognosy of Enicostemma littorale: A review
}

\author{
Rajamani Saranya ${ }^{1}$, Thirunavukkarasu Thirumalai ${ }^{2}$, Munisami Hemalatha ${ }^{1}$, Ranganathan Balaji ${ }^{1}$, Ernest David ${ }^{*}$ \\ ${ }^{1}$ Department of Biotechnology, Thiruvalluvar University, Serkadu, Vellore-632115, Tamilnadu, India \\ ${ }^{2}$ Post graduate and Research Department of Zoology, Physiology Wing, Voorhees College, Vellore-632001, Tamilnadu, India
}

\section{ARTICLE INFO}

Peer reviewer

MA Naidu, Editor of IJPBA, M. Pharm, Ph.D., Reader \& HOD of Pharmaceutics, Mandsaur Institute of Pharmacy, Mandsaur (M.P.).

Tel: 09406674035

E-mail: ijpbaeditormip@gmail.com

Comments

The article is well presented with sufficient study results and imbibing traditional value of $E$. littorale.

(Details on Page 83 )
ABSTRACT

Traditional medicine system of India comprised varieties of plants which are playing a significant role in curing diseases from ancient times. Among them, Enicostemma littorale blume (E. littorale) a perennial herb of the family Gentianaceae is cosmopolitan in occurrence in India. The bittery natured plant acts as a laxative, helps in curing fever, rheumatism, skin diseases, abdominal disorders, snake bite, obesity and helps to regulate blood sugar levels. The plant constituents have been reported for possessing antimicrobial, antioxidant, antiulcer, antiinflammatory, hypolipidaemic, hepatoprotective and hypoglycemic properties. This review provides a bird's eye view about geographical distribution, physicochemical parameters, phytoconstituents and pharmacological properties of E. littorale.

KEYWORDS

Enicostemma littorale, Folklore, Hypoglycemic, Medicinal plant

\section{Introduction}

The use of different parts of the medicinal plant in traditional medicinal system viz., Ayurveda, Siddha and Unani to treat various ailments is in vogue for several centuries. Medicinal plants act as an alternative source for treating several ailments since their usage is increasing day by day[1]. Approximately 72000 plant species were estimated for having medicinal properties. Of which, India recognizes 3000 plant species for having medicinal values. Enicostemma littorale Blume (E. littorale) plays a vital role in human healthcare. The plant parts of E. littorale such as leaves, roots were used in traditional practice for treating several ailments like malaria, skin diseases, leprosy, diabetes etc. The leaf possesses hypoglycemic, antioxidant, hepatoprotective and hepatomodulatory properties and helps in reducing obesity[2]. Medicinal compounds derived from this plant were considered to be very effective since these were less toxic, eco-friendly, palatable, long shelf life and free from side effects[3]. E. littorale is a good source of iron, potassium, sodium, calcium, magnesium, silica, chloride, sulphate, phosphate and vitamins B and C[4]. According to the World Health Organization (WHO), herbal medicines serve the health needs of about $80 \%$ of the world's population, especially for millions of people in the vast rural areas of developing countries[5].

\section{Uses in folklore medicine}

E. littorale is traditionally used in India as a stomachic, bitter tonic, carminative to reduce fever[6] and as a tonic for appetite loss[7]. In Indian ayurvedic medicine, E. littorale is taken in combination with other herbs, especially for diabetes. E. littorale is administered in ayuvedic pill form for treating type 2 diabetes since it plays a major role in reducing blood glucose and increases serum insulin level and significantly improves kidney function, lipid profile, 
systolic and diastolic blood pressure and pulse rate[8]. $E$. littorale has demonstrated its anti-inflammatory activity, and tumour inhibition in rats[9,10], and the plant possesses a secondary compound namely swertiamarin which shows central nervous system (CNS) depressant effects in rats[11]. Nampalliwar and Godatwar observed that E. littorale enhances glucose-dependent insulin release[12]. The hot aqueous extract of $E$. littorale has also been used by the traditional healers for the treatment of dyspepsia and malaria[3].

\section{Taxonomy}

$\begin{array}{ll}\text { Kingdom: } & \text { Plantae } \\ \text { Subdivision: } & \text { Angiospermae } \\ \text { Class: } & \text { Dicotyledonae } \\ \text { Subclass: } & \text { Gamapetalae } \\ \text { Serius: } & \text { Bicarpellatae } \\ \text { Order: } & \text { Gentianales } \\ \text { Family: } & \text { Gentianacae } \\ \text { Genus: } & \text { Enicostemma } \\ \text { Species: } & \text { Littorale }\end{array}$

Nomenclature: The word Enicostemma is probably formed from the three words, "en" means inside, "icos" means 20 and "stemma" means wreath or circle due to the many flowers arranged in circles in the leaf axils along the stem.

\section{Vernacular names}

The ayurvedic name of $E$. littorale is Nahi, Maja-Makka booti, Vellarugu in Tamil, Vallari in Malyalam, White head in English, Chikka chiraayuta in Kanada, Mamajjakah in Sanskrit, Mamejavo in Gujarati, Nagajivha in Bengal, Chota chirayata in Hindi, Kaviyatu in Hindustani, Nela-guli in Telugu.

\section{Geographical distribution}

This tropical genus is widely distributed in South America, Africa, and Asia. E. littorale grows in many diverse habitats from savannas, grasslands, forests to beaches, from wet to very dry and also survives in a very saline environment.

\section{Morphology of $E$. littorale}

E. littorale is an erect, perennial herb, 5-30 cm tall, simple or branched at the base. Stem cylindric, glabrous with a decurrent ridge below each leaf. Leaves are sessile sometimes narrowed into a petiole-like base, longer than the internodes; lamina $(5.0-8.0 \times 0.3-1.0) \mathrm{cm}$, linear to lanceolate or narrowly oblong, entire, obtuse and mucronate at the apex, somewhat narrowing towards the base, 3-nerved from the base, glabrous. Inflorescence in many flowered auxiliary clusters, numerous in the axils of each pair of leaves. Flowers are white with green lines, drying yellowish, sessile or subsessile; bracts long, shorter than the calyx, lanceolate-acuminate, carinate.

Calyx tube 1-2 mm long; lobes usually unequal, $(0.7-1.5 \times$ $0.4-0.7) \mathrm{mm}$, triangular to lanceolate, acute at the apex and narrowly scarious at the margin, or obovate to subcircular, obtuse and mucronate at the apex, with wide scarious margin. Corolla tube 3.5-6.0 mm long; lobes (1.5-2.0×0.7-1.0) $\mathrm{mm}$, ovate and abruptly narrowing to an acute or mucronate apex. Stamens inserted below the sinuses, just above the middle of the tube; filaments $1.5-2.3 \mathrm{~mm}$ long, with a double hood at the insertion point[13].

\section{Nutritional information}

Daily uptake of $2 \mathrm{~g}$ of $E$. littorale fresh leaves is recommended for diabetic patients since its highly nutritious[8]. The nutritional analysis report of Indian Council of Medical Research suggests that $100 \mathrm{~g}$ of fresh E. littorale contains $140 \mathrm{kcal}$ energy, $7 \mathrm{~g}$ of protein, $0.7 \mathrm{~g}$ of fat, $26.5 \mathrm{~g}$ of carbohydrate, $4.2 \mathrm{~g}$ of fibre, $8.4 \mathrm{~g}$ of minerals, $49.9 \mathrm{mg}$ of iron, $1.641 \mathrm{mg}$ of calcium, $81 \mathrm{mg}$ of phosphorous[4].

\section{Physicochemical properties of $E$. littorale}

The physicochemical properties of powdered leaves of $E$. littorale were evaluated and summerised in Table 1. The values were expressed in w/w[14].

Table 1

Physicochemical parameters obtained by using the leaves of $E$. littorale.

\begin{tabular}{lc}
\hline Parameters & Values $(\% \mathrm{w} / \mathrm{w})$ \\
\hline Loss on drying & 0.198 \\
Ash value & 11.960 \\
Water soluble extractive & 27.650 \\
Alcohol soluble extractive & 24.570 \\
\hline
\end{tabular}

\section{Phytoconstituents of $E$. littorale}

This plant comprises of different chemical compounds. Many compounds have been isolated from the plant, $E$. littorale. Tanna et al. reported that the aerial part of the plant gave $34 \%$ of dry alcoholic extract and $15.7 \%$ of ash[15]. The presence of minerals like iron, potassium, sodium, calcium, magnesium, silica, phosphate, chloride, sulphate and carbonate were estimated in the qualitative analysis of ash. Natarajan and Prasad reported the presence of five alkaloids, two sterols and volatile oil[7]. Betulin, a triterpene sapogenin was also isolated by earlier workers[16]. Monoterpene alkaloids like enicoflavin, gentiocrucine and seven different flavonoids were isolated from the alcoholic extract and the structures were identified as apigenin, genkwanin, isovitexin, swertisin, saponarin, 5-o glucosylswertisin and 5-o glucosylisoswertisin were also isolated by Goshal et al[17]. The presence of catechins, saponins, steroids, sapogenin, triterpenoids, flavonoids and xanthones and a new flavone $\mathrm{C}$-glucoside named as Verticilliside was isolated for the first time this species was reported by Jahan et al[18]. Swertiamarin compound was isolated from E. littorale by using alcoholic extract[19]. Six phenolic acids like vanillic acid, syringic acid, p-hydroxy benzoic acid, protocatechuic acid, p-coumaric acid and ferulic acid were also found by Desai et al[20]. Methanol extract of $E$. littorale was found to be containing different aminoacids like L-glutamic acid, tryptophane, alanine, serine, aspartic acid, L-proline, L-tyrosine, threonine, phenyl alanine, 
L-histidine monohydrochloride, methionine, iso leucine, L-arginine monohydrochloride, DOPA, L-Glycine, 2-amino butyric acid and valine[21].

Swertiamarin is a representative constituent of many crude drugs, which are marketed in Japan and other countries and these crude drugs are normally evaluated by their high swertiamarin content[22,23].

\section{Pharmacological properties of $E$. littorale}

\subsection{Antimicrobial activity of E. littorale}

Tanna et al. reported the antifungal activity of $E$. littorale blume[15]. The chloroform extract shows pronounced activity against Aspergillus niger (A. niger) and negligible activity against Candida albicans (C. albicans) at the concentration of $100,200 \mu \mathrm{g} / \mathrm{mL}$. The ethyl acetate extract shows slight activity against $A$. niger and moderate activity against $C$. albicans. The ethanol extract shows pronounced activity against $A$. niger and $C$. albicans.

Praveena et al. observed that the antimicrobial activity of E. littorale against many pathogenic microorganisms by using different solvents like chloroform, ethyl acetate, methanol, petroleum ether[24]. Among that methanolic and ethyl acetate extract of $E$. littorale showed a prominent antibacterial activity against Staphylococcus aureus, Pseudomonas aeruginosa, Salmonella typhi, Shigella sonnei and antifungal activity against Aeromonas hydrophila, C. albicans.

\subsection{Antihelminthic activity of E. littorale}

Mishra and Shukla reported that E. littorale exhibits antihelminthic effects. Petroleum ether and ethanolic extracts of aerial parts of $E$. littorale Blume were prepared and evaluated separately for finding an antihelminthic effect on adult Indian earthworm, Pheretima posthuma[25]. Five different concentrations of each extracts were used in this antihelminthic activity, in which the time of paralysis and death of the worm were determined. The results indicated that an ethanolic extract of E. littorale was more potent than the petroleum ether extract.

\subsection{Antinociceptive effect of E. littorale}

Many traditional Indian medicinal plants which contain large quantity of secoiridoid, swertiamarin are being used to relieve pain. Iridoids present in a wide variety of medicinal plants possess a large number of medicinal properties. In the study by Jaishree $\mathrm{V}$, in vivo anti-nociceptive activity of swertiamarin isolated from E. axillare was carried out using three different methods in mice[26]. In the hot plate method, a significant increase in the latency period was observed for the treatment with swertiamarin at 100 and $200 \mathrm{mg} / \mathrm{kg}$ body weight after 30 and $45 \mathrm{~min}$. The percent protection observed after 45 min was $109.42,147.42$ and 157.14, respectively, for the standard paracetamol and swertiamarin at 100 and $200 \mathrm{mg} / \mathrm{kg}$ body weight treatments. A significant increase in the tail withdrawal reflex was observed for the swertiamarin treatment at both the doses with percent protections of 150 and 200, respectively. In both these methods, swertiamarin showed potent activity than standard paracetamol. In the acetic acid induced writhing, swertiamarin at 100 and $200 \mathrm{mg} / \mathrm{kg}$ body weight reduced the number of writhes significantly. Dose dependent results were observed in all the three methods and among the two doses, swertiamarin at $200 \mathrm{mg} / \mathrm{kg}$ body weight showed potent activity. These results proved that swertiamarin from $E$. axillare possess both peripheral and central antinociceptive activity[26].

\subsection{Antioxidant activity of E. littorale}

Hyperlipidaemia is an important complication of alcohol induced liver injury since it accumulates cholesterol and triglycerides in the liver as well as in the blood leads to several complications[27]. Thirumalai et al. investigated the hyperlipidaemic condition and antioxidant effects on hepatically injured male albino rats (ethanol induced) by treating with aqueous leaf extract of $E$. littorale at a dosage of $250 \mathrm{mg} / \mathrm{kg}$ body weight. After administration of aqueous leaf extract of $E$. littorale, levels of cholesterol, triglycerides and free fatty acids were decreased in serum and the activity levels of TBARS and lipid peroxidation levels were decreased and SOD, CAT, GPX were increased in liver tissue. He reports that an aqueous leaf extract of $E$. littorale blume has potent restorative effect on hyperlipidaemic and oxidative stress.

Clinically the usages of aminoglycosidic antibiotics were limited since it induces the nephrotoxicity. Oxidative stress is the main reason for this complication. Mukundray et al. investigated the role of $E$. littorale Blume as a promising antioxidant therapy in gentamicin iduced nephrotoxicity in rats[28]. Gentamicin treated animals showed high oxidative stress in mitochondrial as well as post-mitochondrial fractions of renal tissues as evidenced by increased lipid peroxidation levels, activities of antioxidant enzymes, SOD and GPx. Treatment with E. littorale ameliorates antioxidant defense system of mitochondrial as well as postmitochondrial fraction, with better improvement seen in mitochondrial fraction. E. littorale extract was used in antioxidant therapy to counteract mitochondrial and postmitochondrial oxidative stress generated in kidney upon gentamicin treatment, thus prevented nephrotoxicity.

\subsection{Antiulcer and anti-inflammatory activity of E. littorale}

The aerial parts of $E$. littorale against aspirin, ethanol and pyloric ligation induced ulcers in rats and bovine serum albumin (BSA) denaturation were examined for antiulcer and anti-inflammatory effects by Roy et al[29]. The extract was administered to the overnight fasted rats, one hour prior to aspirin or alcohol or pyloric ligation challenge. The ulcer index, tissue GSH levels and lipid peroxidation levels in all the models of ulcers and the volume of gastric secretion, acidity and $\mathrm{pH}$ were estimated in the pyloric ligation model of ulcers. Pre-treatment with the aqueous extract of $E$. littorale showed a dose-dependent decrease in the ulcer index against aspirin, ethanol challenge and pyloric ligation. The prior administration of the aqueous extract also reduces the total acidity, free acidity, volume of gastric secretion and elevated the gastric $\mathrm{pH}$. In addition, it was also observed that the aqueous extract inhibits the serum albumin denaturation in a dose-dependent manner. It was reported that the methanolic extract of $E$. littorale possesses antiulcer activity. And its anti-inflammatory activity may be attributed to the antioxidant potential. 


\subsection{Antitumour activity of E. littorale}

The antitumour activity of methanolic extract of $E$. littorale has been evaluated against Dalton's ascitic lymphoma (DAL) in Swiss albino mice by Kavimani et al. A significant enhancement of mean survival time of methanolic extract of $E$. littorale treated tumour bearing mice was found with respect to control group. Treating with methanolic extract of $E$. littorale enhances peritoneal cell counts. When these methanolic extract of E. littorale treated animals underwent intraperitoneal inoculation with DAL cells, tumour cell growth was found to be inhibited. After 14 days of inoculation, methanolic extract of E. littorale is able to reverse the changes in the haematological parameters, protein and PCV consequent to tumour inoculation[11].

\subsection{Hepatoprotective activity of E. littorale}

Paracetamol induced hepatic injury is commonly used as an experimental model for the study of hepatoprotective effects of medicinal plant extracts and drugs. The histological evaluation and the level of various biochemical parameters in circulation indicated the level of hepatic injury. Highly reactive trichloro free radical formation, which attacks polyunsaturated fatty acids of the endoplasmic reticulum, is responsible for the hepatotoxicity of paracetamol. It produces hepatotoxicity by altering liver microsomal membranes in experimental animals. The study by Gite et al.[30] revealed that the extract was able to reduce all the elevated biochemical parameters since it has hepatotoxin detoxication property. E. littorale possesses a chemical compound called swertiamarin which has antioxidant and hepatoprotective properties against D-GalN induced hepatotoxicity given at 100 and $200 \mathrm{mg} / \mathrm{kg}$ body weight orally for 8 days, which might be due to its in vitro antioxidant activity[31]. The present investigation indicates that the ethanolic extract of $E$. littorale exhibits significant hepatomodulation against oxidative stress induced liver injury by $\mathrm{CCl}_{4}$ in rats through antioxidant potential and free radical scavenging activities along with reduction of fat metabolism[13]. These attributes provide the rationale for the use of $E$. littorale in liver disorders by traditional healers in India[32].

\subsection{Hepatomodulatory activity of E. littorale}

The hepatomodulatory response of ethanol extract of $E$. littorale Blume were examined for oxidative stress induced liver injury by carbon tetrachloride $\left(\mathrm{CCl}_{4}\right)$ in albino wistar male rats. The rats were administered with an extract, orally at the doses of 125,250 and $500 \mathrm{mg} / \mathrm{kg}$ bodyweight per day for 21 consecutive days along with $\mathrm{CCl}_{4}$ at the dose of $0.2 \mathrm{~mL} / \mathrm{kg}$ body weight twice a week with intraperitoneal administration of olive oil, in the ratio of 1:1 treatment. The rats subjected only $\mathrm{CCl}_{4}$ with olive oil, showed remarkable oxidative stress induced liver injury. Supplementation of E. littorale extract significantly increases glutathione, GPx, SOD, CAT, and vitamin-C in the liver, with a dosedependent reduction of the TBARS as evidenced by reduced lipid peroxidation, total cholesterol and triglycerides levels in hepatic cells and it was significantly depleted in the treated group when compared to that of control group. Further, the hepatic marker levels aspartate transaminase and alanine transaminase, alkaline phosphatase, acid phosphatase, gamma glutamyl transpeptidase, lactate dehydrogenase, sorbitol dehydrogenase, total bilirubin, total protein and albumin in serum were also restored to normal level dose-dependently after the supplementation of $E$. littorale extract in comparison to respective controls. Gupta et al. suggested that hepatomodulation by $E$. littorale Blume against oxidative stress mediated through interference with free radical generation and reduction in fat metabolism[13].

\subsection{Antihyperlipidaemic activity of E. littorale}

The aerial part of the $E$. littorale reduces the serum cholesterol level in hepatoma bearing rats which induces hypercholesterolaemia. A component of plant enhances cholesterol acyltransferase by esterification of free cholesterol in the HDL[33]. A new study demonstrates a new property of swertiamarin as a potent lipid lowering agent when compared to atorvastatin and it may also contributes cardioprotective and antiatheroscleroticrole effects. The swertiamarin and atorvastatin when orally fed also lowered the total serum cholesterol and triglycerides[34]. Hypolipidaemic and antioxidant effects were evaluated by administrating an aqueous extract of $E$. littorale to rats $(1.5 \mathrm{~g} / 100 \mathrm{~g}$ body weight/day) along with hypercholesterolaemic diet for 6 weeks. The treatment with this extract decreases the activities of erythrocyte CAT, SOD and LPO levels, with an increase in reduced glutathione levels, liver and kidney cholesterol levels were also decreased in $E$. littorale treated rats when compared to cholesterol fed untreated rats[35].

\subsection{Hypoglycemic activity of E. littorale}

The effect of an aqueous E. littorale whole plant extract on antioxidant defense in alloxan-induced diabetic rats was observed by Prince and Srinivasan[36]. A significant increase in blood glucose, TBARS and hydroperoxides in liver, kidney and pancreas, with an decreased concentration of reduced glutathione and suppressed activities of SOD, CAT and GPx were also observed in alloxan induced diabetic rats. Treating diabetic rats with oral administration of aqueous $E$. littorale whole plant extract daily for 45 days significantly decreases the blood glucose, TBARS, SOD, CAT and GPx. The effectiveness of $E$. littorale extract was compared with standard drug insulin. It was observed that an administration of insulin (6 units $/ \mathrm{kg}$ ) to alloxan induced diabetic rats for 45 days brought back all the parameters to near normal status. E. littorale extract at the dose of $2 \mathrm{~g} / \mathrm{kg}$ was more effective. Hence it can be tried in clinical purpose to overcome these complications.

Vishwakarma et al. standardized the dose dependent effect with hot and cold aqueous extracts of E. littorale for three weeks in STZ induced type 1 diabetic rats[37]. Treatment of diabetic rats with STZ significantly produced the carnial signs of diabetes-mellitus like weight loss, polyuria and polydipsia, increased the fasting blood glucose level and AUC glucose associated with decrease in insulin level. Treatment of diabetic rats with hot aqueous extract of $E$. littorale reduced the food, water intake and glucose and AUC glucose levels and decreased the serum glucose, serum cholesterol and triglyceride levels. TLC finger-print profiles were established for the aqueous extract using high performance thin layer chromatography. Swertiamarin was found to be a major component in hot extract of $E$. littorale 
while it was absent in cold extract. The result suggested that $E$. littorale possesses potential antidiabetic activity and improves lipid profile at a dose of $0.5 \mathrm{~g} / \mathrm{kg}$.

\subsection{Antihyperinsulinemic activity of E. littorale}

Insulin resistance is responsible for the development of hyperglycemia in NIIDM patients. Aqueous extracts of Aegle marmelos and E. littorale reduces hyperglycaemic conditions in diabetic animal. Insulin resistance was induced in wistar rats by fructose rich diet (60\% for 15 days). Treated groups received fructose diet plus aqueous extracts $A$. marmelos (500 $\mathrm{mg} / \mathrm{kg} /$ day) and E. littorale $(2 \mathrm{~g} / \mathrm{kg} /$ day). Body weight, serum glucose, insulin, C-reactive protein and triglycerides levels were estimated after treating with an extract. Gohil et al. reported that the fructose feeding for 15 days significantly increased the serum glucose, insulin, $\mathrm{C}$-reactive protein and triglycerides levels compared to control[38]. Administration of aqueous extracts of $A$. marmelos and $E$. littorale for 15 days prevented hyperglycemia and hyperinsulinemia induced by a diet high in fructose.

\subsection{Diabteic neuropathy activity of E. littorale}

Poor glycemic control and oxidative stress is one of the main reasons for the development of diabetic neuropathy. The protective effects of $E$. littorale Blume was investigated for hypoglycemic and antioxidant effect in alloxan induced diabetic neuropathy in male Charles foster rats by Bhatt et al[39]. Nociceptive responses were compared by formalin and tail flick in hot immersion test in both diabetic and non diabetic rats. Treating with E. littorale extract for 45 days significantly improved nociception in diabetic rats. The changes in lipid peroxidation and antioxidant enzymes like SOD, GPx and CAT levels, decrease in Na-K $\mathrm{K}^{+}$ATPase activity were also restored by $E$. littorale treatment. This study provides an experimental evidence for the preventive effect of $E$. littorale on nerve function and oxidative stress in animal model of diabetic neuropathy. Hence, E. littorale may be clinically tried for treating diabetic neuropathy since it was used as a folklore medicine in diabetic patients.

\subsection{E. littorale as a new target for islet neogenesis}

Gupta et al. highlighted an islet neogenic property of one herbal plant $E$. littorale Blume[40]. An active herbal compound SGL-1 was isolated and purified from extract of E. littorale and used to differentiate two model stem cell lines PANC-1 and NIH3T3 which showed tremendous islet neogenic potential and significant islet yield compared to control serum free medium. Morphological, molecular and immunological characterization of newly generated islet like cellular aggregates proved them differentiated and positive for islet hormones. Functional characterization of ICA's confirmed significant glucose responsive insulin release. This preliminary data does offer exciting possibility of alternate source for increasing islet mass which can be used for the treatment of diabetic patients.

\section{Conclusions}

This review furnishes the presence of several phytochemical components in E. littorale and its pharmacological properties. The recent evidences shows an effective role of swertiamarin, a phytochemical compound derived from $E$. littorale. It also showed anti-inflammatory, antimalarial, hepatomodulatory, hepatoprotective, antihyperglycemic, hypoglycemic, antioxidant, antitumor, hypolipidemic and antihelminthic activities of $E$. littorale. This review may focus scientists to develop clinical studies which might be of great scientific contribution for the society. The importance of medicinal plants in traditional healthcare practices provides clues to new areas of research and in biodiversity conservation.

\section{Conflict of interest statement}

We declare that we have no conflict of interest.

\section{Acknowledgements}

Authors are thankful to Department of Biotechnology, Thiruvalluvar University, Vellore, Tamilnadu for providing facilities during preparation of this article.

\section{Comments}

\section{Background}

E. littorale Blume has been used in traditional medicine system for various ailments. Several workers conduced systematic scientific study on the usage of different parts of the plant in curing diseases.

\section{Research frontiers}

$E$. littorale usage in traditional medicine and the systematic study of various plant parts and their active ingredients against various ailments are well documented.

\section{Related reports}

The article is well documented with folklore medicinal properties which lead to a systematic study on their efficacy and isolation of active ingredients.

\section{Innovations and breakthroughs}

The various medicinal uses against various ailments of the parts of $E$. littorale were recorded consistently for reference and for further probe.

\section{Applications}

This article could help to lead to the discovery of new plant based drugs.

\section{Peer review}

The article is well written and presented with sufficient study results.

\section{References}

[1] Akhtar H. Antioxidant potential of dried Enicostemma littorale. Pak Bio Sci 2011; 14(20): 956-957. 
[2] Gite VN, Pokharkar RD, Chopade VV, Takate SB. Hepatoprotective activity of Enicostemma axillare in paracetamol induced hepatotoxicity in albino rats. Int J Phar life Sci 2010; 1(2): 50-53.

[3] Murali B, Upadhyaya UM, Goyal RK. Effect of chronic treatment with Enicostemma littorale in non insulin dependent diabetic rats. J Ethnopharmacol 2002; 81: 199-204.

[4] Sathishkumar R, Lakshmi PTV, Annamalai A. Effect of drying treatment on the content of antioxidants in Encostemma littorale Blume. Res J Med Plant 2009; 3(3): 93-101.

[5] Sharma KA, Kumar R, Mishra A, Gupta R. Problems associated with clinical trials of Ayurvedic medicines. Rev Bras Farmacogn Braz J Pharmacogn 2010; 20(2): 276-281.

[6] Sankaranarayanan S, Bama P, Ramachandran J, Kalaichelvan PT, Deccaraman M, Vijayalakshimi M, et al. Ethnobotanical study of medicinal plants used by traditional users in Villupuram district of Tamil Nadu, India. J Med Plants Res 2010; 4(12):1089-1101.

[7] Garad MC, Upadhya MA, Kokare DM, Itankar PR. Aerial parts of Enicostemma littorale Blume serve as antipyretic and antacid: in vivo and in vitro evaluations. Pharmacogn Commun 2012; 2(3): 4245.

[8] Upadhyay UM, Goyal RK. Efficacy of E. littorale in type 2 diabetic patients. Phyto Res 2004; 18: 233-235.

[9] Leelaprakash G, Mohan Dass S. In-vitro anti-inflammatory activity of methanol extract of Enicostemma axillare. Int J Drug Dev Res 2011; 3(3): 189-196.

[10] Laxman S, Bala P, Kachwala Y, Nancy P. Pharmacological standardization of Enicostemma littorale Blume. Pharmacogn J 2010; 2(16): 12-20.

[11] Kavimani S, Manisenthilkumar KT. Effect of methanolic extract of Enicostemma littorale on Dalton's aseptic lymphoma. J Ethnopharmacol 2000; 71: 349-352.

[12] Nampalliwar AR, Godatwar P. Antidiabetic activity of Enicostemma littorale leaf extracts in streptozotocin induced diabetic rats. Int J Ayur Herbal Med 2012; 2(3): 514-547.

[13] Gupta RS, Singh D. Hepatomodulatory role of Enicostemma littorale Blume against oxidative stress induced liver injury in rats. Afr J Agri Res 2007; 2: 131-138.

[14] Paivera J, Nogueira I. Encostemma littorale herbal summary. (Gentianaceae: Potalieae: Faroinae: E. Littorale) Flora Zambesica. 1990; Vol 7, Part 4.

[15] Tanna S, Shukla VJ, Prajapati PK. Physico-phytochemical evaluation of aqueous extract of Mamajjaka Enicostemma littorale. Int J Pharm Bio Arch 2010; 1(3): 309-312.

[16] Dymock W, Warden CJH, Hooper D. Pharmacographica Indica. Calcutta: Thacker, Spink \& Co.; 1893, vol 2, p. 516.

[17] Ghosal SS, Sharma AK, Chaudhuri PV. Chemical constituents of Gentianaceae IX: natural occurrence of Erythrocentaurin in Enicostemma hissopifolium and Swertia lawii. J Pharm Sci 1974; 63: 944-945.

[18] Jhan E, Perveen S, Malik A. Verticilliside, a new flavones C-glucoside form Enicostemma verticillatum. J Asi Nat Prod Res 2009; 11: 257-260.

[19] Leelaprakash G, Mohan Dass S. Antimicrobial activity and phytochemical screening of methanol extract of Enicostemma axillare. Int J Pharm Pharm Sci 2012; 4(1): 342-348.

[20] Desai PD, Ganguly AK, Govindachari TR, Joshi BS, Kamat VN, Manmade $\mathrm{AH}$, et al. Chemical investigation of some Indian medicinal plants: Part II. Ind J Chem 1966: 4: 457-459.

[21] Sathiskumar R, Lakshmi PTV, Annamalai A. Comparative analyses of non enzymatic and enzymatic antioxidants of Enicostemma littorale Blume. Int J Pharma Bio Sci 2010; 1(2): 1-16.

[22] Jaishree V, Badami S, Krishnamurthy PT. Antioxidant effect and hepatoprotective effect of ethyl acetate extract of Enicostemma axillare (Lam) Raynal against $\mathrm{CCl}_{4}$ induced liver injury in rats. Ind J Exp Bio 2010; 48: 896-904.

[23] Maroo J, Vasu VT, Gupta S. Dose dependent hypoglycemic effect of aqueous extract of Enicostemma littorale Blume in alloxan induced diabetic rats. Phytomedicine 2003; 10(2-3): 196-199.

[24] Praveena P, Sudarsanam D. In vitro antimicrobial activity studies on Enicostemma littorale (Lam), Raynal Whole plants. Int J Curr Res 2011; 11(3): 123-124.

[25] Mishra S, Shukla P. In vitro anthelmintic activity of Enicostemma littorale Blume. Int J Pharma Sci Res 2011; 2(5): 1193-1196.

[26] Jaishree V, Badami S, Kumar MP, Tamizhmani T. Antinociceptive activity of Swertaimarin isolated from Enicostemma axillare. Phytomedicine 2009; 16: 227-232.

[27] Thirumalai T, Therasa VS, Elumalai EK, David E. Hypolipidemic and antioxidant effect of Enicostemma littorale Blume. Asian Pac J Trop Biomed 2011; 1: 381-385.

[28] Mukundray NB, Chauhan K, Gupta S, Pillai P, Pandya C, Jyoti V, et al. Protective effect of Enicostemma littorale Blume methanolic extract on Gentamicin induced Nephrotoxicity in rats. Am J Inf Dis 2011; 7(3): 83-90.

[29] Roy SP, Niranjan CM, Jyothi TM, Shankrayya MM, Vishawanath KM, Prabhu K, et al. Antiulcer and anti-inflammatory activity of aerial parts of Enicostemma littorale Blume. J Young Pharm 2010; 2(4): 369-373.

[30] Gite VN, Pokharkar RD, Chopade VV, Takate SB. Hepatoprotective activity of Enicostemma axillare in paracetamol induced hepato-toxicity in albino rats. J Pharmocol 2010; 1: 5053.

[31] Vaijanathappa J, Badami S, Bhojraj S. In vitro antioxidant activity of Enicostemma axillare. J Heal Sci 2008; 524-528.

[32] Rajasekaran A, Arivukkarasu R, Murugesh S. Hepatoprotective effect of Adenema hyssopifolium G.Don (Gentianaceae) in carbon tetrachloride-induced hepatotoxicity in rats. Trop J Pharm Res 2010; 9(2): 157-163.

[33] Gopal TK, Vidyadhar S, Reddy UM, Chamundeeswari, Reddy S, Saidulu A, et al. In vitro antifungal activity of various extracts of Enicostemma littorale. J Biotech Biother 2011; 1:2.

[34] Vaidya H, Rajani M, Sudarsanam V, Padh H, Goyal R. Swertiamarin: A lead from Enicostemma littorale Blume for antihyperlipidaemic effect. Eur J Pharmacol 2009; 617(1-3): 108112.

[35] Gopal R, Udayakumar R. Enzymatic and non-enzymatic antioxidant activity in $\mathrm{p}-\mathrm{DAB}$ induced hepatocarcinoma in rats. Int J Pharmacol 2008; 4(5): 369-375.

[36] Prince PSM, Srinivasan M. Enicostemma littorale Blume aqueous extract improves the antioxidant status in alloxan induced diabetic rat tissues. Acta Pol Pharm Drug Res 2005; 62(5): 363-367.

[37] Vishwakarma SL, Rakesh SD, Rajani M, Goyal RK. Evaluation of effect of aqueous extract of Enicostemma littorale Blume in streptozotocin- induced type 1 diabetic rats. Ind J Exp Bio 2010; 48: $26-30$.

[38] Gohil TA, Patel JK, Vaghasiya JD, Manek. Antihyperglycemic and antihyperinsulinemic effect of aqueous extract of Aegle marmelos leaf and Enicostemma littorale. Ind J Pharm 2008; 40(2): 66-91.

[39] Bhatt NM, Barua S, Gupta S. Protective effect of Enicostemma littorale Blume on rat model of diabetic neuropathy. Am J Infect Dis 2009; 5(2): 106-112.

[40]Gupta S, Dadheech N, Singh A, Soni S, Bhonde RR. Enicostemma littorale: A new therapeutic target for islet of neogenesis. Int J Int Bio 2010; 9(1): 50. 